\title{
Pemodelan Virtual Reality Studi Kasus Pengenalan Laboratorium Komputer Universitas Indraprasta
}

\author{
Dudi Parulian ${ }^{1}$, Sri Mardiyati ${ }^{2}$ \\ ${ }^{1,2}$ Teknik Informatika, Universitas Indraprasta, Jakarta Selatan, Indonesia \\ e-mail: ${ }^{1}$ paruliandudi@gmail.com, ${ }^{2}$ srimardiyati05@gmail.com
}

Submitted Date: February $26^{\text {th }}, 2021$

Revised Date: June $04^{\text {th }}, 2021$
Reviewed Date: June 02 $2^{\text {nd }}, 2021$

Accepted Date: June $15^{\text {th }}, 2021$

\begin{abstract}
Utilization of information technology can be applied in many fields, one of which is the field of education. One of the tools in the field of education is a building that supports teaching and learning activities. Buildings in educational activities have many forms and facilities, one of which is a computer laboratory building at Indraprasta University. The laboratory building for new students requires more complete information because it includes many facilities. Utilizing information technology in the form of virtual reality to describe the laboratory building helps new students get to know more about the facilities owned by the university. Introduction of virtual reality laboratories to new students with Virtual Reality. The object displayed is the model and layout of the Laboratory. By using Sketchup, Unity, and Android Studio with the Android platform. Researchers created a simple Virtual Reality application that is easy to use. This application displays Virtual Reality computer laboratory objects along with the laboratory information. This application can be used in several versions of Android smartphones such as 4.1.1 and above.
\end{abstract}

Keywords: Virtual Reality; Computer lab; Sketchup; Android;

\section{Abstrak}

Pemanfaatan teknologi informasi dapat diterapkan dibanyak bidang salah satunya adalah bidang pendidikan. Salah satu perangkat bidang pendidikan adalah gedung penunjang kegiatan belajar mengajar. Gedung dalam kegiatan pendidikan mempunyai banyak bentuk dan fasilitas salah satunya adalah gedung laboratorium computer di Universitas Indraprasta. Gedung laboratorium bagi mahasiswa baru membutuhkan informasi lebih lengkap karena didalamnya banyak fasilitas. Memanfaatkan teknologi informasi berupa virtal reality untuk menggambarkan gedung laboratoium membantu mahasiswa baru mengenal lebih banyak tentang fasilitas yang dimiliki universitas. Pengenalan virtual reality laboratorium kepada mahasiswa baru dengan Virtual Reality. Objek yang ditampilkan adalah model dan tata ruang dari Laboraturium tersebut. Dengan menggunakan Sketchup, Unity, dan Android Studio ber-platform Android. Peneliti membuat sebuah aplikasi Virtual Reality sederhana yang mudah digunakan. Aplikasi ini menampilkan objek Virtual Reality laboraturium komputer beserta informasi laboraturium tersebut. Aplikasi ini dapat digunakan dibeberapa versi smartphone Android seperti 4.1.1 ke atas.

Kata Kunci: Virtual Reality; Laboratorium Komputer; Sketchup; Android;

\section{Pendahuluan}

Teknologi pada saat ini berkembang sudah sangat cepat dan pesat terlebih pada bidang teknologi dan informasi. Teknologi informasi dapat berbentuk telepon pintar dengan macam sistem operasi baik itu Android maupun ios. Beragam aplikasi menarik dapat dijalankan diperangkat telepon pintar ini. Virtual reality merupakan teknologi memungkinkan pengguna dapat berinteraksi dengan lingkungan yang dapat disimulasikan komputer atau telepon pintar.

Virtual reality adalah teknologi yang memberikan sebuah pengalaman lebih bagus melebihi kacamata 3D. Virtual reality membangkitkan suasana yang lebih real dengan menggunakan sejumlah alat tertentu, serta 
memungkinkan penggunanya untuk merasakan seperti ada di dunia nyata padahal pengguna sedang berada di dalam simulasi video maupun dibeberapa permainan tertentu. Aplikasi virtual reality yang berbasis Android yang terintegrasi dengan smartphone ini bisa digunakan dalam beberapa bidang contohnya, game, simulasi video suatu keadaan tata ruang bangunan, maupun periklanan.

Aplikasi ini bisa digunakan untuk salah satu kegiatan kampus Universitas Indraprasta. Misalnya, pada kegiatan orientasi studi dan pengenalan kampus, pengenalan kampus pada lingkungan sekitar maupun dunia luar, untuk menarik peminat umum untuk melanjutkan sekolah ke universitas tersebut. Karena banyak sekali bagian- bagian kampus yang harus diketahui oleh mahasiswa salah satu contohnya adalah Laboraturium Teknik Informatika.

\section{Metode Penelitian}

Metode penelitian yang dilakukan untuk memenuhi tujuan penelitian dan pembuatan aplikasi ini adalah, pengumpulan dan analisis informasi, Pengumpulan informasi dilakukan dengan cara observasi langsung pada objek Laboraturium tersebut, studi pustaka serta pencarian informasi di internet tentang implementasi virtual reality. Perancangan antarmuka aplikasi menggunakan Unity untuk mendesain tampilan pada aplikasi di smartphone. Kemudian, pemodelan laboraturium dan lingkungan sekitarnya menggunakan software Sketchup 2016. Pemodelan dilakukan dengan menggunakan sketchup dibuat sama persis seperti aslinya. Aplikasi bantu unutk membuat sistem ini menggunakan tools seperti android SDK, Cardboard SDK, dan Unity3D.

Implementasi pada bagian ini adalah penggabungan objek, lalu aplikasi yang dibuat diujicoba. Uji coba dilakukan menggunakan Unity dan smartphone yang dikombinasikan dengan perangkat head-mounted device bernama Ant-VR.

\section{Perancangan Sistem}

Aplikasi Virtual Reality ini digunakan untuk memperlihatkan lingkungan sekitar laboraturium komputer. Desain objek tiga dimensi dibuat menggunakan software Sketchup, Selanjutnya diolah menggunakan Unity3D. Dengan Unity3D, maka dapat mengontrol objek yang dibuat agar memberikan respon dari suatu kondisi dan kejadian tertentu. Simulasi dapat menggunakan sebuah Head Mounted Display (HMD) yang dibuat oleh google dengan nama google cardboard. Aplikasi ini dibuat dengan menggunakan program pemodelan Sketchup, Game Engine Unity, Cardboard SDK For Unity Package.

Pembuatan aplikasi ini melewati beberapa tahapan pembuatan sebelum diaplikasikan pada perangkat target. Tahap-tahap pembuatan secara alur dapat dilihat pada penjelasan berikut:

a. Analisa dan Pengumpulan Informasi.

Pada tahap ini dilakukan observasi terhadap objek yang dibuat yaitu Laboraturium Teknik Informatika kampus Universitas Indraprasta, dilakukan pengukuran ukuran ruangan dan pengambilan gambar sebagai contoh pemodelan objek serta mengumpulkan informasi yang dibutuhkan dalam pembuatan simulasi ini.

b. Tahap Perancangan pada Sketchup dan Eksport Objek menjadi 3D.

Pada tahap ini, dilakukan perancangan objek yang ditampilkan dalam lingkungan virtual seperti bangunan laboraturium, kursi, meja komputer, monitor, CPU dan lain lain. Selain melakukan perancangan, tahap ini juga melakukan proses import objek yang diambil dari 3D warehouse.

c. Tahap pengintegrasian Unity, Cardboard SDK For Unity Package.

Setelah seluruh informasi dikumpulkan, tahap berikutnya adalah pengintegrasian seluruh komponen aplikasi pembangun lingkungan Virtual reality. Hal ini meliputi proses import Cardboard SDK For Unity package ke dalam Unity.

d. Tahap Penyatuan Objek pada Unity.

Setelah objek telah dibuat, maka dilanjutkan ke tahap berikutnya yaitu penyatuan objek dan pemberi animasi di dalam aplikasi Unity. Pada tahapan ini pula, dilakukan pembuatan tampilan menu untuk interkasi pengguna saat aplikasi pertama kali dijalankan.

e. Tahap Uji Coba dan Implementasi.

Setelah penyatuan objek dan pembuatan animasi selesai, simulasi tersebut dapat diuji coba langsung dengan menekan tombol play pada Unity. Jika simulasi berjalan dengan lancar, maka dapat dibuat menjadi sebuah aplikasi android (apk), sehingga dapat langsung diinstalasi pada perangkat android pengguna.

\section{Struktur Navigasi}

Navigasi pada aplikasi virtual reality ini terdiri dari menu utama yang terdapat tiga buah pilihan yaitu, tampilan Lab-TI VR, peraturan, 
Informasi, dan Keluar. Masing-masing pilihan tersebut memiliki fungsinya masing - masing.

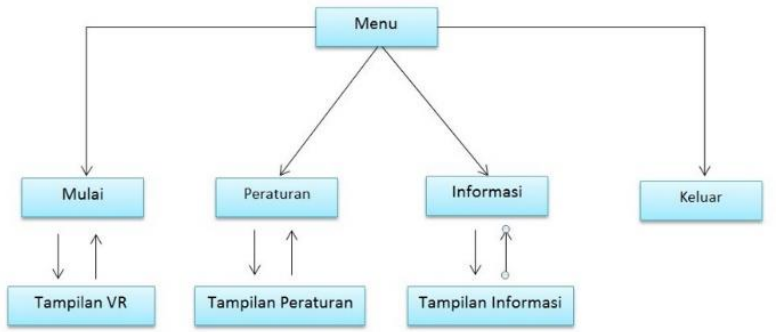

Gambar 1 Struktur Navigasi Sistem

Pembuatan model tiga dimensi laboraturium komputer dengan menggunakan software Sketchup. Pembuatan model dibagi menjadi beberapa tahapan antara lain pembuatan lantai dasar, tiang bangunan, tembok bangunan, kusenkusen, meja dan peralatan laboratorium lainya. Kemudian komposisi lainnya ditambahkan pada software Unity3D.

Saat hendak memulai untuk pemodelan objek baru pada Sketchup, maka langkah pertama yang harus dilakukan adalah membuka software Sketchup itu sendiri, Sketchup yang peneliti gunakan adalah versi terbaru pada tahun 2016 pada gambar 2

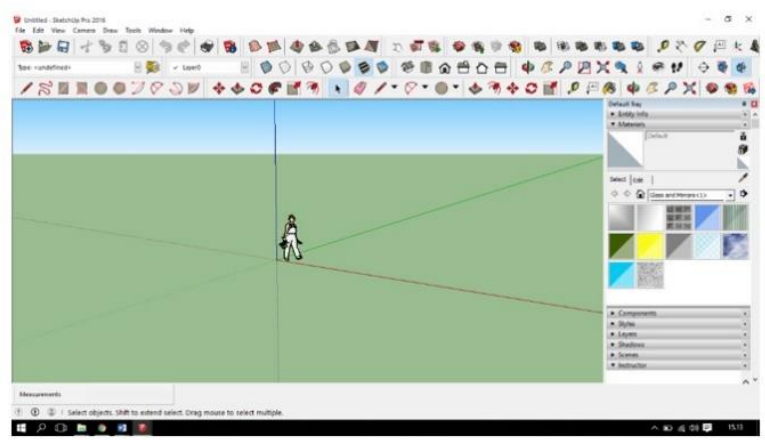

Gambar 2. Tampilan Aplikasi Sketchup

Pada gambar 2 adalah gambar tampilan awal dari aplikasi pembuat objek 3D Sketchup. Halaman utama menampilkan seluruh menu dan perintah aplikasi.

\section{Pembuatan Laboraturium Komputer}

Lembar kerja terbuka peneliti melakukan proses pembuatan bangunan secara berkala seperti pembuatan lantai, tembok, dinding, kusen, meja, kursi dan ornamen lainya. Setelah semua objek dibentuk selanjutnya adalah penggabungan semua objek menjadi satu bentuk bangunan.
Pembuatan lantai disesuaikan dengan kebutuhan misalnya lantai dengan dimensi $12,57 \mathrm{~m}$ x 15,83m maka ketiklah "12,57m; 15,83m" dan ukuran ketebalan lantai $0,20 \mathrm{~m}$ atau sekitar $20 \mathrm{~cm}$. Objek gambar di berikan tekstur agar tampilan lebih natural beri tekstur objek lantai tersebut dengan White Subway Tile. Agar objek-objek yang di bentuk menjadi satu kesatuan maka pilih make component maka jadilah lantai yang di inginkan.

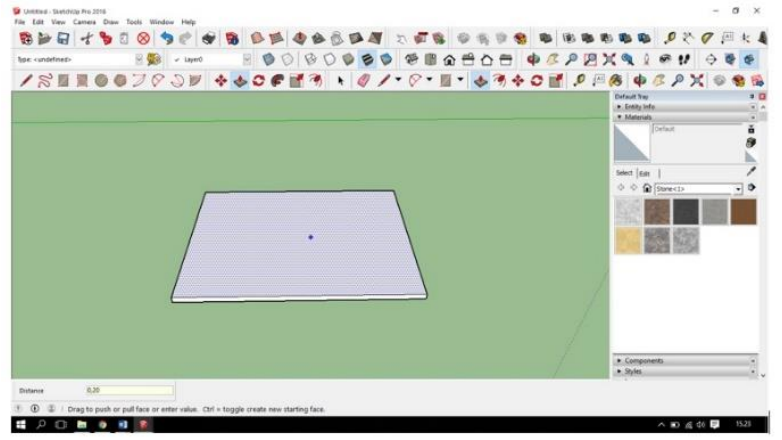

Gambar 3. Hasil Pembuatan Objek Lantai.

Gambar 2 adalah bentuk objek lantai yang sudah jadi. Objek lantai diberi tekture agar terlihat lebih natural seperti bantuk asli.

\section{Pembuatan Tembok}

Pembuatan tembok utama pada bangunan laboraturium dengan ukuran $0,60 \mathrm{~m} \times 0,60 \mathrm{~m}$ dan tinggi $2,50 \mathrm{~m}$. Tembok kedua dengan ukuran panjang $4,27 \mathrm{~m}$, tinggi $2,50 \mathrm{~m}$ dan ketebalan $0,15 \mathrm{~m}$.

Setelah tembok jadi agar objek menjadi satu kesatuan maka klik dua kali pada objek tersebut lalu klik kanan pada mouse pilih Make Component maka jadilah tembok pertama sesuai dengan ukuran yang diinginkan.

Bentuk objek tembok diwarnai dengan menggunakan tool "Bucket", pada kolom deafult tray, yang terdapat pada sisi kanan lembar kerja lalu klik Material, lalu pilih colors pilih warna cokelat tua untuk frame, klik warna lalu warnai objek dengan cara klik pada frame. Bagian dalam pilih warna cokelat muda, klik pada warna yang dipilih, lalu warnai objek bagian dalam tadi dengan cara klik pada objek dalam.

Kemudian satukan objek yang telah diputar dengan objek sebelumnya dengan menggunakan tool "Move". Klik pada sudut objek kemudian tarik hingga 4 sisi objek terbentuk menjadi kotak. Satukan objek kolom yang telah dibuat sebelumnya dengan objek skin.

\section{Pembuatan Lantai}




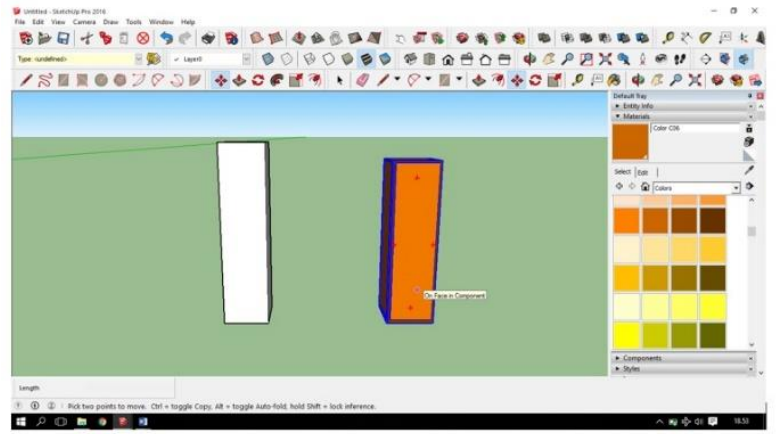

Gambar 4. Proses PembuatanTiang.

Gambar 4 merupakan bagian tiang dari tembok. Bagian tiang ini dibentuk sejumlah sudut dan kebutuhan dari bentuk struktur bangunan.

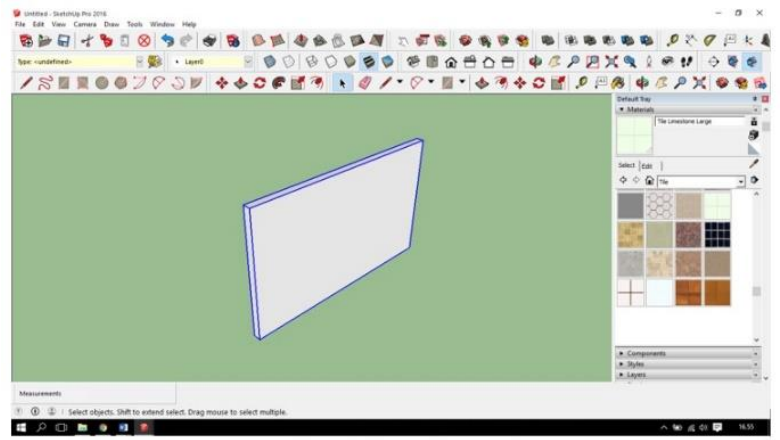

Gambar 5. Proses Pembuatan Tembok

Gambar 5 adalah bentuk tembok salah satu sisi. Bentuk ini kemudian dibuat sebanyak tembok yang ada pada semua sisi dan dibuat sesuai dengan struktur bangunan.

\section{Pembuatan Jendela}

Pembuatan jendela dibagi menjadi 3 bagian yaitu Kusen, Frame Kaca dan Kaca. Buat persegi panjang dengan ukuran $3 \mathrm{~m} \times 1,5 \mathrm{~m}$. Pembuatan jendela sesuai ketebalan $0,15 \mathrm{~m}$. Kemudian warnai kusen dengan menggunakan tool "Bucket", dengan cara klik tool "Bucket" pilih warna kemudian klik pada kusen tersebut maka kusen akan berwarna.

Pembuatan Frame dengan persegi panjang dengan ukuran $0,73 \mathrm{~m} \times 1,4 \mathrm{~m}$ buat ketebalan $0,05 \mathrm{~m}$ kemudian buat persegi panjang pada permukaan objek. Make Component. Warnai objek dengan Bucket, pilih warna coklat yang sama dengan warna kusen.

Pembuatan kaca berbentuk persegi panjang dengan ukuran $0,63 \mathrm{~m} \times 1,30 \mathrm{~m}$ ukuran ketebalan yaitu $0,005 \mathrm{~m}$. Setelah ketiga item tersebut jadi satukan objek kaca dengan frame kaca menggunakan tool "Move", letakan objek kaca tepat pada titik tengah frame kaca
Lakukan langkah tadi hingga terbentuk empat buah frame kaca dan kaca, blok semua objek frame kaca dan kaca menggunakan tool "Move" untuk memindahkan, klik pada sudut objek, satukan dengan objek kusen yang sebelumnya telah dibuat klik 3 kali pada objek, klik kanan pilih Make Component.

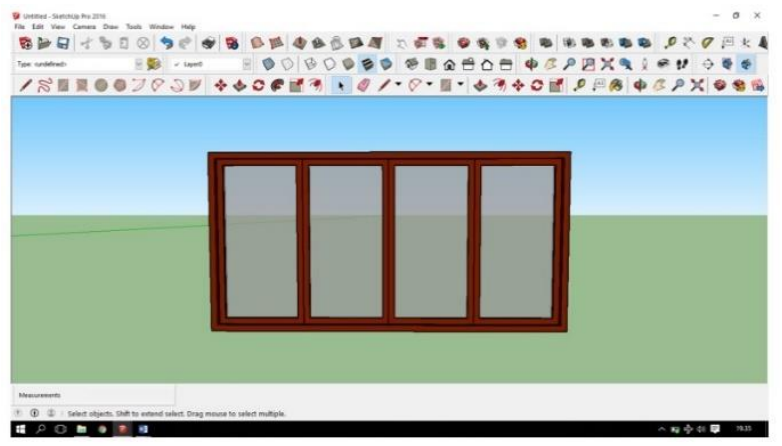

Gambar 6. Pembuatan Objek Jendela.

Gambar 6 adalah gambar objek jendela. Gambar jendela ini akan di perbanyak sesuai degan jumlah jendela yang terdapat pada gedung.

\section{Membuat Atap Laboraturium}

Pembuatan bagian atap dengan membuat persegi panjang dengan Rectangle. Dimensi atap $13,55 \mathrm{~m}$ x 13,55m maka ketiklah "13,55m; $13,55 \mathrm{~m} "$. Gambar yang telah dibuat tadi dengan ukuran ketebalan lantai $0,50 \mathrm{~m}$ atau sekitar $50 \mathrm{~cm}$. Agar objek menjadi satu kesatuan maka klik dua kali pada objek tersebut lalu klik kanan pada mouse pilih Make Component.

\section{Pembuatan Furniture dan Perangkat Keras}

Laboratorium Komputer terdapat beberapa perangkat penunjang berlangsungnya pembelajaran bagi praktikan di laboratorium tersebut beberapa diantaranya adalah monitor, $\mathrm{CPU}$ (Central Processing Unit), mouse, meja komputer, tirai, kursi, layar proyektor dan proyektor. Peneliti membuat 1 contoh proses pembuatan perangkat penunjang bagi praktikan. Perangkat penunjang yang disebutkan diatas ini tidak dibuat secara manual melalui proses desain melainkan menggunakan tool 3D warehouse. Contohkan cara membuat monitor PCdengan sketchup tidak perlu dibuat secara manual karena terdapat pada 3D warehous yang terdapat pada toolbars.

Model-model tersebut dapat diunduh untuk kemudian digunakan pada lembar kerja sketchup, disini peneliti mengambil model monitor PC yang sangat mirip dengan model PC pada Laboraturium teknik informatika universitas Indraprasta. Setelah 
objek monitor yang dirasa sudah cukup pas dan mirip dengan model yang aslinya maka klik gambar model tersebut, lalu klik download yang terdapat pada sebelah kiri window tersebut.

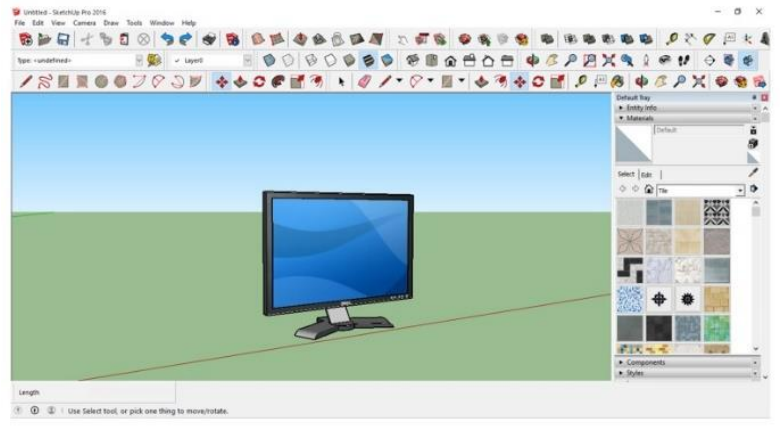

Gambar 7. Pembuatan Objek Perangkat Keras

Gambar 7 adalah contoh objek yang tersedia pada Aplikasi Sketchup. Bentuk objek lain dapat dipilih dan dowonlod untuk dijadikan materi pembuatan objek.

\section{Penggabungan Objek - Objek}

Setelah semua objek dibuat maka tahap akhir dari pembuatan objek Laboraturium Teknik Informatika adalah melakukan penggabungan serta penataan tempat dimana objek tersebut harus diletakan sama persis pada laboraturium tersebut.

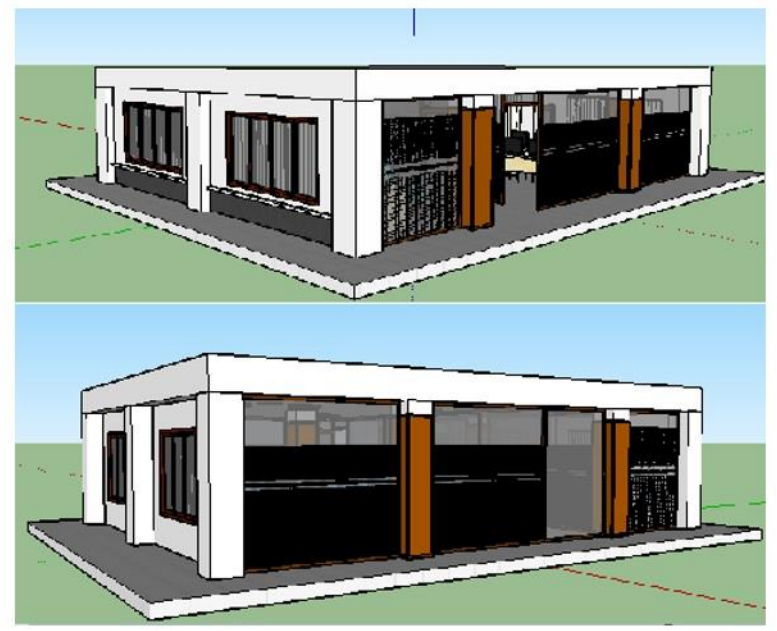

Gambar 8. Penggabungan objek-objek desain

Gambar 8 adalah gambar skema gedung laboratorium computer. Desain gambar dibuat sesuai dengan keadaan sebenarnya.

\section{Menjadikan Objek Tiga Dimensi}

Setelah proses pemodelan objek selesai maka langkah berikutnya adalah pengintegrasian objek kedalam unity. Sebelumnya export objek kedalam bentuk tiga dimensi dan berformat .fbx lalu save objek tersebut agar bisa masuk kedalam unity.

\section{Rancangan Tampilan Labkom TI VR}

Proses pengintegrasian model objek tersebut kedalam unity, buka aplikasi game engine unity beri nama project yang akan dibuat pada tahap awal. Proses berikutnya memasukan asset project, komponen-komponen yang akan dibutuhkan, dalam membangun labkom TI VR. Pilih semua komponen yang dibutuhkan untuk dimasukan kedalam project $3 \mathrm{D}$.

Proses penggabungan Cardboard SDK for Unity kedalam asset dengan import package pilih custom package. Agar Cardboard bisa berjalan tanpa harus menggunakan kontroler maka tambahkan script pada Cardboard SDK tersebut dengan cara klik kanan pada kolom asset, create pilih C\#script. Setelah script menyatu dengan cardboard main bisa di uji coba dengan tombol Play yang berada di atas scene.

Pemberian efek agar suasana mirip seperti diluar lingkungan laboraturium dengan memberikan beberapa objek berbentuk pohon disekitaran objek bangunan. Tambahkan efek langit dengan warna langit yang berwarna cerah. Mengatur lebih dahulu lighting pada windows agar bisa merubah kondisi langit pada skybox.

Setelah pengintegrasian cardboard SDK for unity dan asset-asset pendukung dibangunnya scene mulai. Pengujian scan play seperti apa tampak Laboraturium Teknik Informatika dalam bentuk VR ini dengan cara klik Button Play.

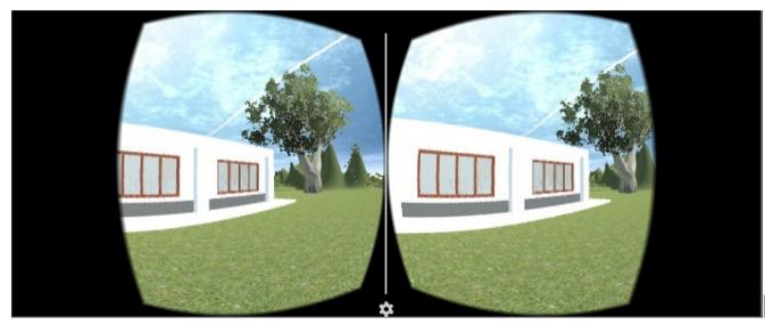

Gambar 9 Tampilan Virtual Objek Laboratorium

Gambar 9 adalah gambar yang terlihat dalam bentuk Virtual Realitiy. Pengguna seakan masuk ke dalam dimensi gambar secara 3Dimensi.

\section{Proses Instalasi Aplikasi}

Kompilasi aplikasi dilakukan untuk menghasilkan sebuah file berekstensi apk untuk melakukan instalasi aplikasi pada perangkat 
android. Langkah-langkah installasi pada pernangkat android seperti berikut:

a. Hubungkan perangkat android ke PC dengan menggunakan kabel USB

b. Pilih file berekstensi apk hasil kompilasi yang bernama LakomTI_VR.apk

c. Salin file tersebut ke perangkat android pada sebuah direktori

d. Cari file tersebut pada file manager dimana tempat tadi menyimpan file apk

e. Klik pada file berekstensi apk tersebut pilih install

\section{Implementasi Aplikasi}

Setelah proses instalasi dilakukan, selanjutnya adalah menjalankan aplikasi tersebut dengan alat-alat yang tersedia. Pasangkan handphone dengan cardboard. Jalankan aplikasi Labti_VR.apk pada android dengan pilih menu mulai. Pasang ke kepala pengguna, untuk menjalankan mode VR tersebut cukup touch layar android.

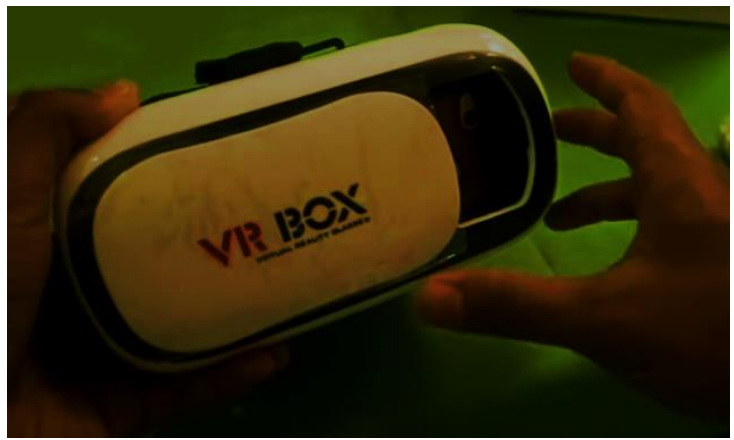

Gambar 10. Menggunakan VR Box

$\mathrm{S}$

Gambar 10 adalah contoh alat untuk menjalankan aplikasi VR. Alat ini dinamakan VR Box

\section{Kesimpulan}

Hasil penelitian berupa aplikasi Aplikasi Virtual Reality Pengenalan Laboraturium Teknik Informatika Universitas Indraprasta Menggunakan Google Cardboard berhasil dengan baik. Aplikasi ini dapat dipublikasikan kapada calon mahasiswa untuk lebih mengenal Laboratorium Komputer yang ada dilingkungan kampus.

Calon mahasiswa baru mengenal lingkungan Laboraturium komputer dari tempat dimanapun berada tanpa harus mengunjungi laboraturium tersebut.

Aplikasi ini melakukan simulasi Lingkungan Laboraturium secara virtual dengan menggunakan sudut pandang pertama agar memberi kesan bahwa pengguna tersebut sedang berada didalam lingkungan tersebut dengan bantuan Head mounting device.

a. Pengguna dapat berinterkasi dengan dunia di dalam lingkungan virtual tersebut selayaknya interaksi pada dunia nyata.

b. Aplikasi ini dapat digunakan pada perangkat android minimal requirement 4.1 Jelly Bean dan memiliki layar minimal 5 inch serta memiliki sensor gyroscope pada smarthphone tersebut.

c. Aplikasi ini juga membutuhkan Google Cardboard sebagai Head Mounting Device.

d. Pengoptimalan pada bagian desain objek dan bagian grafis dengan menggunakan objekobjek yang memiliki jumlah polygon lebih kecil. Penggunaan objek dengan polygon kecil dapat meningkatkan performa objek memperbaiki tampilan agar terlihat lebih bagus

\section{Referensi}

Ausburn, L. J. (2009). A Cross-case Analysis of Gender Issues In Dekstop Virtual Reality Learning Environments. Journal of Industrial Teacher Education, 46(3) 51-89.

Brimingham.Wodaski, R. (1993). Virtual Reakity Madness. Indiana: Sams Publishing.

Goldstone, W. ( 2009). Unity Game Development Essential. New York: Packt Publishing.

Huang, H. (2011). Applying Situated Learning in a Virtual Reality System to Enhance Learning Motivation. International Journal of Information and Education Technology, 1(4) 298-302.

Indraprastha, A. (2009). The Investigation on Using Unity 3D Game Engine. I Urban Design Study: ITB J.ICT, 3(1) 2009 1-18.

Media, I. (2016, Juni 27). Pengertian Aplikasi, Jenis dan Contohnyar Retrieved from https://www.idjoel.com/: https://www.idjoel.com/

Moeleong, L. (2013). Implementasi Cluster Computing Untuk Render Animasi. E-Jurnal Teknik Elektro dan Komputer, Vol 2, No 3 (2013).

Safaat, N. (2011). Pemprograman aplikasi Mobile Smartphone dan Tablet PC berbasis Android. Bandung: Informatika.

Winkler, F. (2018, 12 01). Unity3D Workshop. Retrieved from web.ics.purdue.edu: web.ics.purdue.edu

Woodford, C. (2015. , 12 3). Virtual Reality. Retrieved from Virtual Reality: http://www.explainthatstuff.com 